\title{
Sub-Synchronous Interaction Analysis between DFIG Based Wind Farm and Series Compensated Network
}

\author{
Wang, Yun; Wu, Qiuwei; Kang, Shaoli
}

Published in:

Proceedings of 2016 IEEE PES Asia-Pacific Power and Energy Engineering Conference

Link to article, DOI:

10.1109/APPEEC.2016.7779527

Publication date:

2016

Document Version

Publisher's PDF, also known as Version of record

Link back to DTU Orbit

Citation (APA):

Wang, Y., Wu, Q., \& Kang, S. (2016). Sub-Synchronous Interaction Analysis between DFIG Based Wind Farm and Series Compensated Network. In Proceedings of 2016 IEEE PES Asia-Pacific Power and Energy Engineering Conference (pp. 359-363). IEEE. https://doi.org/10.1109/APPEEC.2016.7779527

\section{General rights}

Copyright and moral rights for the publications made accessible in the public portal are retained by the authors and/or other copyright owners and it is a condition of accessing publications that users recognise and abide by the legal requirements associated with these rights.

- Users may download and print one copy of any publication from the public portal for the purpose of private study or research.

- You may not further distribute the material or use it for any profit-making activity or commercial gain

- You may freely distribute the URL identifying the publication in the public portal 


\section{Sub-Synchronous Interaction Analysis between DFIG Based Wind Farm and Series Compensated Network}

\author{
Yun Wang \\ College of Mechatronics and Control \\ Engineering, \\ Shenzhen University, \\ Shenzhen, P. R. China \\ wangyun@szu.edu.cn
}

\author{
Qiuwei $\mathrm{Wu}$ \\ Centre for Electric Power and Energy \\ (CEE), \\ Department of Electrical Engineering, \\ Technical University of Denmark (DTU) \\ Kgs. Lyngby, Denmark
}

\author{
Shaoli Kang \\ Hengqin Development Limited Liability \\ Company \\ Zhuhai, P.R.China
}

\begin{abstract}
This paper analyzes the sub-synchronous interaction (SSI) phenomenon between the doubly fed induction generator (DFIG) based wind farm (WF) and the series capacitor compensated network. The possible types of SSI in the DFIG based WF are studied. The factors influencing the SSI of DFIG based WF are investigated. The large signal stability and small signal stability of the DFIG based WF with different series compensation (SC) level and wind speed are simulated and compared.
\end{abstract}

Index Terms-- doubly-fed induction generator (DFIG), series compensation, sub-synchronous interaction (SSI), wind power.

\section{NOMENCLATURE}

\begin{tabular}{|c|c|}
\hline Csc & Series capacitor \\
\hline$K_{p}, K_{i}$ & Parameters of PI controller \\
\hline$K_{s c}$ & Series compensated level \\
\hline$L g, L l s, L l r$ & GSC, stator, rotor leakage inductances \\
\hline$L L, L T$ & Transmission line, transformer inductances \\
\hline LLT & Submission of $L L$ and $L T$ \\
\hline$L s, L r, L m$ & Stator, rotor, and mutual inductances \\
\hline$R_{L}$ & Transmission line equivalent resistance \\
\hline$R_{s}, R_{r}$ & Stator, rotor resistances \\
\hline$U_{d c}, u_{g}, u_{s}$ & Converter DC, grid and stator voltages \\
\hline$X_{s c}$ & Series capacitor reactance \\
\hline$f_{n}$ & Electrical resonance frequency \\
\hline$f_{r}, f_{s}$ & Rotor, synchronous frequencies \\
\hline$i_{g}, i l, i r, i_{s}$ & GSC, grid line, rotor and stator currents \\
\hline$i_{s d}, i_{s q}$ & Stator currents of $d, q$ axis \\
\hline$i r d, i r q$ & Rotor currents of $d, q$ axis \\
\hline$i r d^{*}, i r q^{*}$ & References of $i r$ controller at $d, q$ axis \\
\hline$s$ & Laplace coefficient \\
\hline slip & DFIG slip ratio \\
\hline$u r d, u r q$ & Rotor voltages of $d, q$ axis \\
\hline uscd, $u_{s c q}$ & Series capacitor voltages of $d, q$ axis \\
\hline$u s d, u s q$ & Stator voltages of $d, q$ axis \\
\hline
\end{tabular}

This work was supported in part by the National Natural Science Foundation of China (51407118) and the Shenzhen Government Science Foundation (JCYJ20140509172609161, GJHZ20130408173747552).

\begin{abstract}
$\omega_{\text {slip }}, \omega r \quad$ Slip, rotor angular speeds
$X_{s c} \quad$ Series capacitor reactance

- Mark of rotor parameter converted to stator

Mark of rotor parameter converted to stator
\end{abstract}

\section{INTRODUCTION}

With rapid growth of wind power in the power system, the sub-synchronous interaction (SSI) may occur when a wind farm (WF) is connected to alternating-current (AC) transmission lines with series-capacitor compensation [1]. The doubly-fed induction generator (DFIG) based WFs are especially susceptible to the SSI, which can build up within hundreds of milliseconds [2]. The SSI can cause damages very fast, i.e. leading to excessive currents both at the wind turbine level and the point of common coupling (PCC), and creating significant over-voltages at the utility level before relays detect [1]. Such events have been reported in the Electric Reliability Council of Texas (ERCOT) system and other places [3]-[4].

The SSI in the WF has been investigated using the methods of studying stability and sub-synchronous oscillation problems in power systems, i.e. the eigenvalue analysis, the root locus method and the frequency scanning [3]-[5]. The SSI in the WF is different from traditional thermal power generation systems, what is usually excited by the subsynchronous torsional interaction and the shaft torque amplification, the sub-synchronous induction generator effect (SSIGE) and the sub-synchronous control interactions (SSCI). The SSIGE and SSCI are the two main types in the WF [6]-[7]. The two types of SSI have been analyzed in order to find the possible factors that influence currents oscillation and system stability. In [5]-[8], it is indicated that the cause of SSIGE in the DFIG based WF is similar to the one in conventional power generation systems When wind speed reduces or the SC level increases, the absolute value of the equivalent rotor resistance may exceed the sum of the stator resistance and network resistance at the electrical resonance frequency, and it will destabilize the system. The SSCI is an interaction between the generator controller of wind turbines and the series compensated transmission system [6], [9]. The existing 
research shows that the possible sub-synchronous oscillation frequency under the SSCI is not fixed and can be in a wide frequency band above the slip frequency. The SSCI can build up very quickly and will cause severe damages [3], [5] if not effectively suppressed.

Although previous studies indicate some characteristics of the SSI phenomenon, the factors influencing the SSI of DFIG based WF have not been fully given. The system uncertainties such as the SC level, grid line reactance and wind speed are not fully considered. This paper considers all the above factors as well as the controller parameters, and analyzes the influence of each factor on the SSI phenomenon and the system stability by the eigenvalue analysis and time-domain simulation.

This paper is organized as follows. Section II develops the system model using the state-space representation. Section III analyzes the small stability of the IGE and the SSCI by the eigenvalue analysis. In Section IV, the large-signal stability is studied by time domain simulation, including the system response under grid voltage faults and SC level changes, followed by conclusions.

\section{SYSTEM MODELING}

The WF model for SSI studies usually adopts the IEEE first benchmark model (FBM). The system diagram is shown in Fig. 1, where the WF is aggregated as a wind turbine (WT). A 1.5 MW DFIG based WT model is used in this paper scaled up to represent a $90 \mathrm{MW}$ WF. All DFIG variables are marked in the motor direction. The parameters of the whole system are listed in the Appendix.

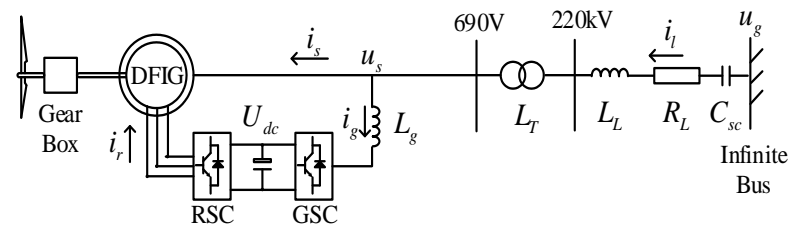

Figure 1. Study diagram with aggregated DFIG based WF

For the DFIG based WT, the power flow from the stator side and the rotor side is approximately (1-slip) /slip [10], [11] Neglecting the power loss of the converters, it has $i l \approx i_{s} /$ (1slip). So the transmission line reactance and resistance, $L_{L T}=$ $L T+L L$ and $R L$, can be converted from the grid side to the stator side as $L L T^{\prime}=L L T /(1-$ slip $)$ and $R L^{\prime}=R L /(1-$ slip $)$. The SC level is defined as $K_{s c}=1 /\left(\omega_{B}^{2} C_{s c} L L T\right)$, and its range is $0 \leq K_{s c} \leq 1$. Based on the basic time domain DFIG mathematical model [6], a 6th order system model with both the generator model and the grid model at the synchronously rotating $d q$ frame can be described by state-space realization as (1), marked as $G\left(A, B_{1}, B_{2}, C, D\right)$. The state-space variable vector is marked as $\boldsymbol{x}=\left[i_{s d}, i_{s q}, i_{r d}, i_{r q}, u_{s c d}, u_{s c q}\right]$. The output vector is $\boldsymbol{y}=\left[i_{r d}, i_{r q}\right]$. The input vector is $\boldsymbol{u}=$ $\left[u_{r d}, u_{r q}\right]$. The disturbance vector is $\boldsymbol{d}=\left[u_{s d}, u_{s q}\right]$. The detailed description of the parameter matrixes in (1) are given in (2) and (3) at the end of the paper.

$$
\left\{\begin{array}{c}
\dot{\boldsymbol{x}}=A \boldsymbol{x}+\left[B_{1}, B_{2}\right][\boldsymbol{u}, \boldsymbol{d}]^{T} \\
\boldsymbol{y}=C \boldsymbol{x}+D \boldsymbol{u}
\end{array}\right.
$$

As [9]-[12] indicate, the system instability of the DFIG based WF is mainly caused by the rotor current controller of the rotor side converter (RSC). The RSC current controller commonly uses the proportion integral (PI) regulator, which can be described by the transfer function,

$$
\boldsymbol{u}=\left(k_{p}+\frac{k_{i}}{S}\right)(\boldsymbol{r}-\boldsymbol{y})
$$

where $\boldsymbol{r}=\left[i_{r d}^{*} i_{r q}^{*}\right]$ is the reference vector of the rotor current controller.

\section{SSI ANALYSIS}

The eigenvalues and modal analysis based on (1) and (4) are given in this section. The modal analysis can validate the small signal stability and provide the necessary information to understand the root cause of the SSI phenomenon.

\section{A. Open loop System}

There are several uncertain factors of the controlled system model, including the wind speed, transmission line reactance, and the series capacitor. The change of wind speed can be described by slip. The SC level can describe different series capacitor. Fig. 2 shows the eigenvalue loci of the open-loop system when the slip increases from -0.3 to 0.3 with the SC level being 0 (red), $50 \%$ (blue) and $100 \%$ (green) respectively, where the starting point is marked with ' $*$ ' and the ending point is marked with "o,

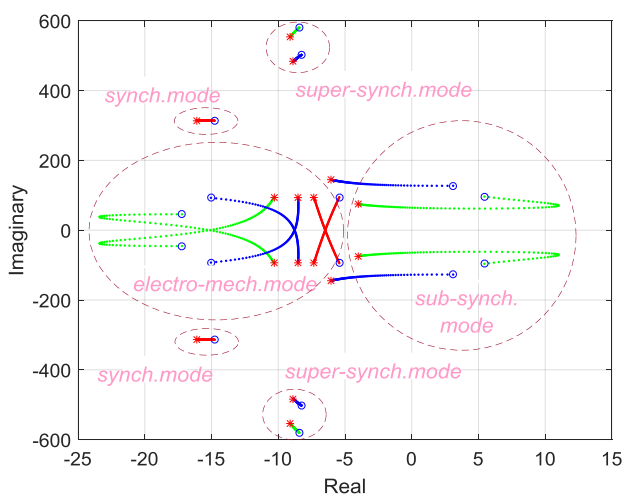

Figure 2. Eigenvalue loci of the open-loop system with slip from -0.3 to 0.3

It is seen from the red curve that there are two system modes without the series compensation. One is the synchronous mode related to the synchronous frequency $f_{s}$. The other is the electro-mechanical mode related to the rotor current frequency. It is seen, with the slip increasing, the eigenvalues move towards the imaginary axis, and the system stability becomes worse. After adding series capacitor(s), as the blue and green curves show, the synchronous mode is replaced with a super-synchronous mode and a subsynchronous mode. It is seen, when the slip increases, the eigenvalues of the sub-synchronous mode moves from the left 
half plane to the right half plane. It is a typical SSIGE phenomenon which makes the system unstable.

Fig. 3 shows the eigenvalue loci of the open-loop system when the SC level increases from 0 to $100 \%$ with the slip being 0.3 (red), 0 (green) and -0.3 (blue), respectively. As the SC level increases, the system stability becomes worse. There is a maximum eigenvalue value when the slip is 0.3 . After crossing the maximum value, the sub-synchronous mode move towards the imaginary axis, and the stability margin becomes smaller.

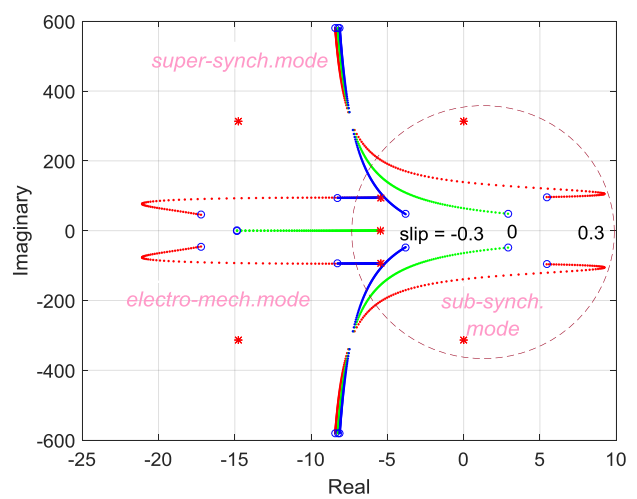

Figure 3. Eigenvalue loci of the open-loop system with SC level from 0 to $100 \%$

Fig. 4 shows the eigenvalue loci of the open-loop system when $R_{L}$ increases from $50 \%$ to $150 \%$ with the slip being 0.2 and the SC level being 50\%. The stability of both the subsynchronous mode and the super-synchronous mode gets better as $R_{L}$ increases.

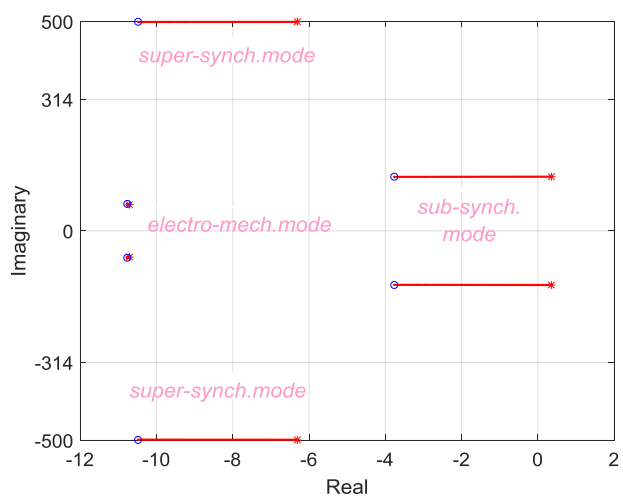

Figure 4. Eigenvalue loci of open-loop system with $R L$ from $50 \%$ to $150 \%$

Fig. 5 shows the eigenvalue loci of the open-loop system when $L_{L T}$ increases from $50 \%$ to $150 \%$ with the slip being 0.2 and the SC level being 50\%. It is seen the stability of both the sub-synchronous mode and the super-synchronous mode becomes worse as $L L T$ increases.

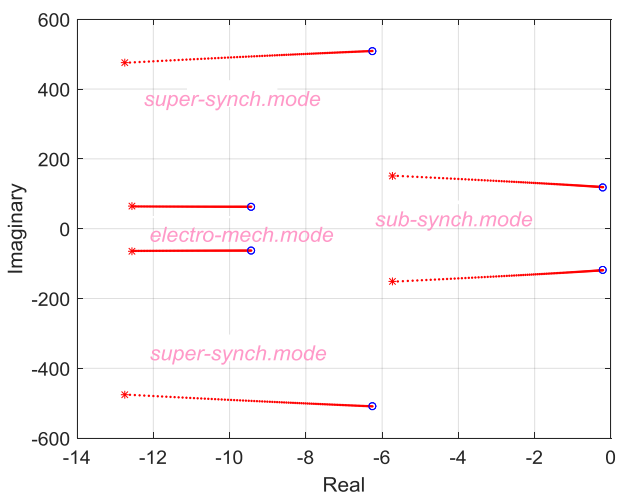

Figure 5. Eigenvalue loci of the open-loop system with $L L T$ from $50 \%$ to $150 \%$

\section{B. Closed loop System}

Fig. 6 shows the eigenvalue loci of the closed-loop system when the slip increases from -0.3 to 0.3 with the SC level being 0 (red), $50 \%$ (blue) and $100 \%$ (green), respectively. It is seen, comparing with the open-loop system modes, a pair of new modes related to the PI controller are added for the closed-loop system. Compared to Fig.2, it is seen the PI controller worsens the stability of the system with series compensation as a typical SSCI phenomenon. The system is unstable as the slip increases from -0.3 to 0.3 with SC level as $50 \%$ and $100 \%$, in which all eigenvalues of the subsynchronous mode are located at the right half plane.

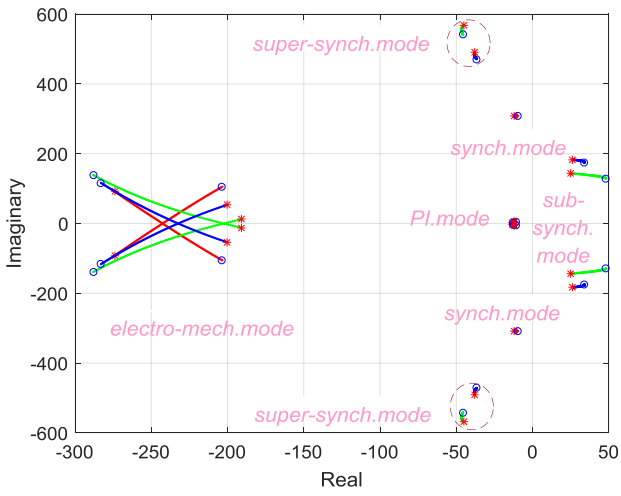

Figure 6. Eigenvalue loci of the closed-loop system with slip from -0.3 to 0.3

Fig. 7 shows the eigenvalue loci of the closed-loop system when the SC level increases from 0 to $100 \%$ with the slip being 0.3 (red), 0 (green) and -0.3 (blue), respectively. Similar to Fig. 3, it is seen, as the SC level increases, the system stability becomes worse. 


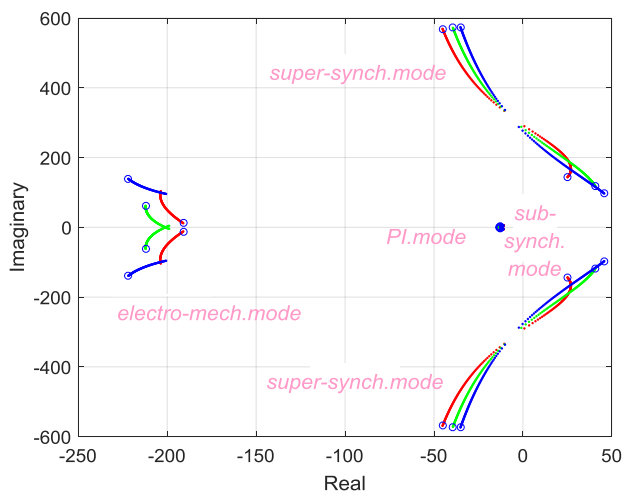

Figure 7. Eigenvalue loci of the closed-loop system with SC level from 0 to $100 \%$

Fig. 8 and Fig. 9 shows the eigenvalue loci of the closedloop system as $K p$ increases from 0.01 to 10 , and $\mathrm{Ki}$ increases from 0.01 to 20 , respectively. The slip is 0.2 and the SC level is $50 \%$. It is seen, the instability of the sub-synchronous mode is worsened by increasing $K p$. It is seen in Fig. 9 the instability of the sub-synchronous mode becomes worse as $\mathrm{Ki}$ increases.

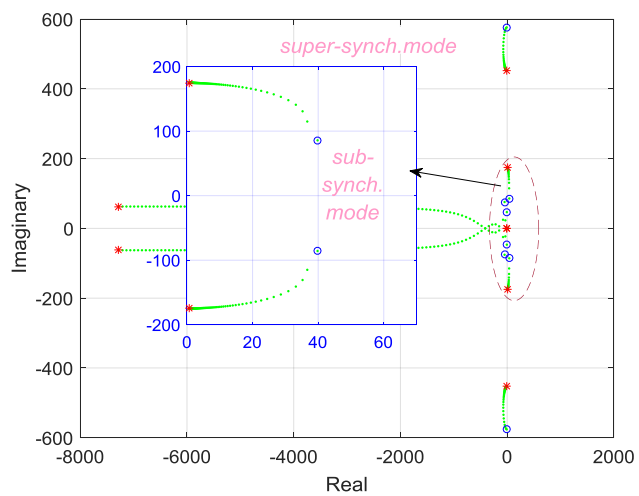

Figure 8. Eigenvalue loci of closed-loop system with $\mathrm{Kp}$ from 0.01 to 10

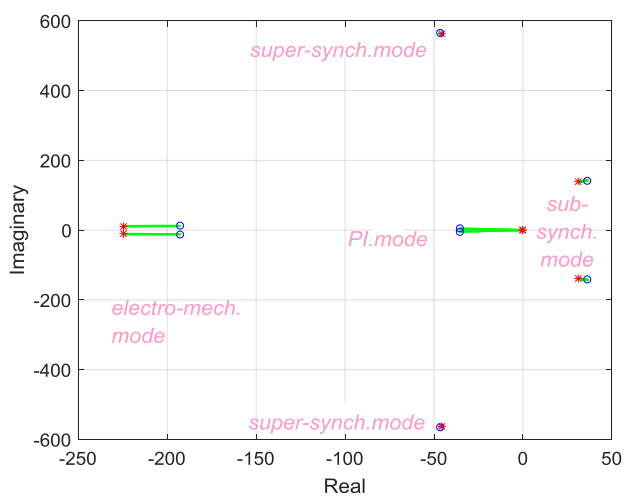

Figure 9. Eigenvalue loci of closed-loop system with Ki from 0.01 to 20

\section{SimULANTION STUDIES}

The system large-signal stability was studied by time domain simulations. Fig. 10 shows the currents and output power with the PI control under the SC disturbance. The parameter $K_{s c}$ changes from $5 \%$ to $50 \%$ at $5 \mathrm{~s}, R_{L}$ and $L_{L T}$ are nominal value, and the slip is -0.2 . It is seen $i_{s d}$ and $i_{r d}$ showing obvious sub-synchronous oscillations from $5 \mathrm{~s}$ and the oscillation frequency of $i_{r d}$ is about $23 \mathrm{~Hz}$. The active power also shows obvious oscillations.
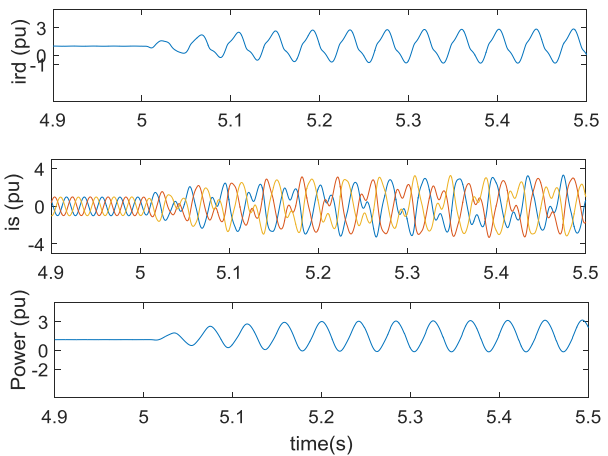

Figure 10. Performance of $i_{s,} i_{r}$ and active power

Fig. 11 shows $i_{s d}, i_{r d}$ and the DC voltage under grid voltage faults. A three phase to ground voltage fault with $50 \%$ dip depth occurred from $5 \mathrm{~s}$ to $5.3 \mathrm{~s}$. The SC level is $10 \%$. It is seen, after a dynamic process, a sub-synchronous oscillation component of $i_{r}$ and $U_{d c}$ is excited after the grid fault. The current oscillation is observed during and after the grid fault.
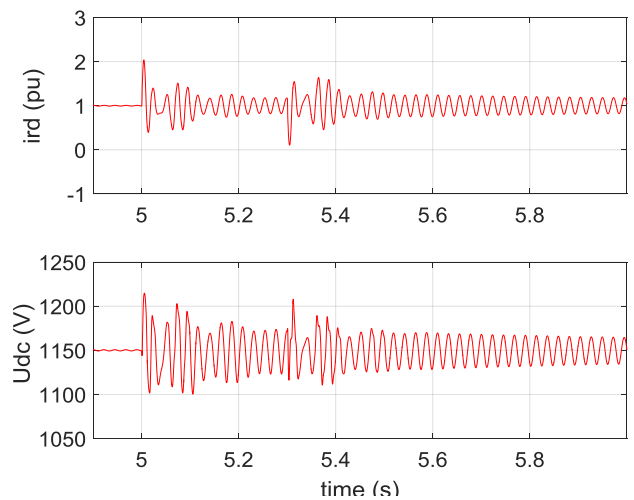

Figure 11. Dynamic performance under grid voltage fault

\section{CONCLUSION}

In this paper, the SSI phenomenon between the DFIG based WF and the series capacitor compensated network is analyzed by the eigenvalues and modal analysis as well as time domain simulations. The factors influencing the SSI of DFIG based WF are analyzed and the conclusions are given as follows.

1) The wind speed, reflected as the rotor speed or slip affects the SSI of DFIG. With wind speed decreases, the damping of the SSI decreases and the sub-synchronous mode becomes more unstable.

2) The series capacitor, reflected as the SC level, has great influence on the SSI of DFIG. With the SC level increasing, the sub-synchronous mode is more unstable. 
3) The PI parameters greatly influence the SSI of DFIG. With the parameters of $k i$ or $k p$ increasing (e.g. the bandwidth of PI increasing), the stability of sub-synchronous mode worsens. So the conventional PI control method must be improved, not only keeping dynamic performance of control system with enough bandwidth, but also improving the mitigation ability on SSI.

4) The grid impedance influences the SSI of DFIG. The grid resistance increase improves the damping to mitigate sub-synchronous oscillation. The grid reactance increase reduces the damping of the SSI and the stability of the subsynchronous mode becomes worse.

\section{REFERENCE}

[1] L. C. Gross, "Sub-Synchronous Grid Conditions: New Event, New Problem, and New Solutions," in Proc. 37th Annu. Western Protective Relay Conf., 2010, pp. 1-19.

[2] I. S. R. T. Force, "First benchmark model for computer simulation of subsynchronous resonance," IEEE Trans. Power Appar. Syst., vol. 96, no. 5, pp. 1565-1572, Sep. 1977.

[3] M. Sahni, Y. Cheng, and Y. Zhou, "Sub-synchronous interaction in Wind Power Plants- part II: An ercot case study," in 2012 IEEE Power and Energy Society General Meeting, 2012, pp. 1-9.

[4] K. Narendra, D. Fedirchuk, R. Midence, N. Zhang, A. Mulawarman, P. Mysore, and V. Sood, "New microprocessor based relay to monitor and protect power systems against sub-harmonics," in 2011 IEEE Electrical Power and Energy Conference, 2011, pp. 438-443.

[5] B. Badrzadeh, M. Sahni, D. Muthumuni, and A. Gole, "General methodology for analysis of sub-synchronous interaction in wind power plants," in 2013 IEEE Power \& Energy Society General Meeting, 2013, pp. $1-1$.

[6] H. A. Mohammadpour and E. Santi, "Sub-synchronous resonance analysis in DFIG-based wind farms: Definitions and problem identification - Part I," in 2014 IEEE Energy Conversion Congress and Exposition (ECCE), 2014, pp. 812-819.

[7] L. Fan and Z. Miao, "Mitigating SSR Using DFIG-Based Wind Generation," IEEE Trans. Sustain. Energy, vol. 3, no. 3, pp. 349-358, Jul. 2012.

[8] L. Fan, R. Kavasseri, Z. L. Miao, and C. Zhu, "Modeling of DFIGBased Wind Farms for SSR Analysis," IEEE Trans. Power Deliv., vol. 25, no. 4, pp. 2073-2082, Oct. 2010.

[9] A. E. Leon and J. A. Solsona, "Sub-Synchronous Interaction Damping Control for DFIG Wind Turbines," IEEE Trans. Power Syst., vol. 30, no. 1, pp. 419-428, Jan. 2015.

[10] R. Pena, J. C. Clare, and G. M. Asher, "Doubly fed induction generator using back-to-back PWM converters and its application to variablespeed wind-energy generation," IEE Proc. - Electr. Power Appl., vol. 143, no. 3, p. 231, 1996.

[11] S. Muller, M. Deicke, and R. W. De Doncker, "Doubly fed induction generator systems for wind turbines," IEEE Ind. Appl. Mag., vol. 8, no. 3, pp. 26-33, 2002.

[12] F. Mei and B. Pal, "Modal Analysis of Grid-Connected Doubly Fed Induction Generators," IEEE Trans. Energy Convers., vol. 22, no. 3, pp. 728-736, Sep. 2007.

$$
\begin{aligned}
& A=\frac{\omega_{B}}{L_{m}^{2}-L_{r}\left(L_{s}+L_{L T}^{\prime}\right)}\left[\begin{array}{cccccc}
L_{s}\left(R_{s}+R_{L}^{\prime}\right) & L_{m}^{2} \omega_{s l i p}-\left(L_{s}+L_{L T}^{\prime}\right) L_{r} \omega_{s} & -L_{m} R_{r} & -L_{m} L_{r} \omega_{r} & L_{r} & 0 \\
\left(L_{s}+L_{L T}^{\prime}\right) L_{r} \omega_{s}-L_{m}^{2} \omega_{s l i p} & L_{r}\left(R_{s}+R_{L}^{\prime}\right) & L_{m} L_{r} \omega_{r} & -L_{m} R_{r} & 0 & L_{r} \\
-L_{m}\left(R_{s}+R_{L}^{\prime}\right) & \left(L_{s}+L_{L T}^{\prime}\right) L_{m} \omega_{r} & \left(L_{s}+L_{L T}^{\prime}\right) R_{r} & L_{m}^{2} \omega_{s}-\left(L_{s}+L_{L T}^{\prime}\right) L_{r} \omega_{s l i p} & -L_{m} & 0 \\
-\left(L_{s}+L_{L T}^{\prime}\right) L_{m} \omega_{r} & -L_{m}\left(R_{s}+R_{L}^{\prime}\right) & \left(L_{s}+L_{L T}^{\prime}\right) L_{r} \omega_{s l i p}-L_{m}^{2} \omega_{s} & \left(L_{s}+L_{L T}^{\prime}\right) R_{r} & 0 & -L_{m} \\
\frac{L_{m}^{2}-L_{r}\left(L_{L}+L_{L T}^{\prime}\right)}{\omega_{B} C_{s c}(1-s l i p)} & 0 & 0 & 0 & 0 & L_{m}^{2}-L_{r}\left(L_{s}+L_{L T}^{\prime}\right) \\
0 & \frac{L_{m}^{2}-L_{r}\left(L_{s}+L_{L T}^{\prime}\right)}{\left.\omega_{B}\right)} & 0 & 0 & L_{r}\left(L_{s}+L_{L T}^{\prime}\right)-L_{m}^{2} & 0
\end{array}\right] \\
& B_{1}=\frac{\omega_{B}}{L_{m}^{2}-L_{r}\left(L_{s}+L_{L T}^{\prime}\right)}\left[\begin{array}{cc}
L_{m} & 0 \\
0 & L_{m} \\
-\left(L_{s}+L_{L T}^{\prime}\right) & 0 \\
0 & -\left(L_{s}+L_{L T}^{\prime}\right) \\
0 & 0 \\
0 & 0
\end{array}\right], B_{2}=\frac{\omega_{B}}{L_{m}^{2}-L_{r}\left(L_{s}+L_{L T}^{\prime}\right)}\left[\begin{array}{cc}
-L_{r} & 0 \\
0 & -L_{r} \\
L_{m} & 0 \\
0 & L_{m} \\
0 & 0 \\
0 & 0
\end{array}\right], \quad C=\left[\begin{array}{lllllll}
0 & 0 & 1 & 0 & 0 & 0 \\
0 & 0 & 0 & 1 & 0 & 0
\end{array}\right] \quad D=0
\end{aligned}
$$

